\title{
SIMULATION STUDIES ON MICROWAVE ASSISTED DRYING OF BIOMASS WITH SPECIAL ATTENTION TO THE SIZE OF BIOMASS
}

\author{
Varinder Singh, Nitin Saluja and Amrinder Singh \\ Chitkara University Institute of Engineering and Technology, Punjab, India
}

\begin{abstract}
The crop-waste is available in abundant to generate energy. The energy conversion process involve production of biofuel from crop-waste. This paper considers the conversion of rice straw to energy. The conversion involve the preprocessing of rice straw which includes drying and its conversion to powder form. This paper proposes the microwave assisted drying process for rice straw. The single strand of rice straw is considered in the paper. The Multiphysics simulation is performed to understand the heat generation and heat-transfer rate with variation in the size of rice straw. The proposed process involves the cutting of rice straw to specific sizes. The rice straw size plays an important role in absorbing microwave energy. The heating pattern depends on the mode of transverse electric field interacting with specified size of rice straw. The different modes getting excited in the rice straw depends on its size. It is observed in this paper that the large size of rice straw help in achieving multiple modes in a single strand of rice straw. Hence, it results in optimized microwave process to achieve the uniform heating in rice straw. The cutting of rice straw before microwave processing requires the rice straw to size between $8 \mathrm{~cm}$ to $12 \mathrm{~cm}$.
\end{abstract}

Keywords: Microwave drying, Biomass, Heat transfer, Simulation.

Cite this Article: Varinder Singh, Nitin Saluja and Amrinder Singh, Simulation Studies on Microwave Assisted Drying of Biomass with Special Attention to the Size of Biomass. International Journal of Mechanical Engineering and Technology. 11(4), 2020, pp. 16-24.

https://iaeme.com/Home/issue/IJMET?Volume $=11 \&$ Issue $=4$

\section{INTRODUCTION}

The major non- renewable sources of energy are major contributors to the two-third of world`s electricity production. The contribution of coal and natural gases in producing energy for domestic usage globally is $40.8 \%$ and $21.6 \%$ respectively. It is evident that the last 16 years the earth have witnessed increase of 32.31 Giga tonnes of $\mathrm{CO}_{2}$ [1]. Hence, the researchers focus is to define sustainable and environment friendly energy sources. The crop- 
waste has proven sustainable raw material for production of the energy. The rice straw is available in bulk at the global level. Hence, the rice producing countries like China, India and Indonesia are the potential source of bio-butane[2]. The conversion of rice straw to biofuel requires pre-process of rice straw. The drying is essential pre-processing step require to convert the rice straw to biofuel. The conventional drying process with convection heating and vaporization offers efficiency up-to 25-30\%. The evolution of microwave technology has enabled the energy efficient drying of the rice straw. It is claimed that the output of microwave drying process eases the torrefaction process[3]. The microwave heating during pretreatment severely rupture the surface of biomass and release light hydrocarbons during the torrefaction process. Hence the rice straw after the microwave drying followed by torrefaction results in reduced high heating value (HHV) in comparison to conventional drying process[3]. Hence, the microwave drying is not in practice to dry the rice straw in bulk. The microwave energy has disadvantages of non-uniform microwave heating and the undesired chemical processes which take place due to non-thermal effects of microwave. Hence, the target is to achieve uniform processing of object and control the temperature within the specified range. The advantages of microwave drying process such as the $1 / 6^{\text {th }}$ the time to dry rice straw and the energy efficiency up-to $70 \%$ has triggered research in redefining the process for rice straw drying[4]. The current research focuses on achieving the drying of rice stubble without disrupting the chemical composition required to convert it into bio-mass[5]. The microwave drying depends on physical, electrical and thermal properties of material[6]. The physical properties include size and geometry of the object. The electrical property includes dielectric constant and the loss tangent. The thermal property includes specific heat of capacity and phase transition (P-T) point/latent heat.

This paper analyzes the effect of size and orientation of rice straw on its heating pattern. The analysis also includes the variation in thermal and chemical properties with the size of rice straw in microwave cavity. The analysis allows the definition of uniform heating processes and control the temperature to dry the rice straw as per the requirement of torrefaction process. The analysis is performed with multiphysics computer simulation[7]. The simulation is performed with 3-D structure of rice straw placed inside the microwave cavity. The simulation of microwave heating involves solution to Maxwell's equation simultaneously with heat-transfer equations[8]. The simulation deploys finite difference time domain method to solve the equations with 3-D structure.

\section{MATERIALS AND METHODS}

The analysis performed in a COMSOL Multiphysics software. The three dimensional (3D) cavity is designed which closely resembles the commonly available commercial microwave cavities of BAJAJ1701 MT. The size of the microwave system is tabulated in the Table 1.

The rice straw is defined in cylindrical shape with the radius of $3 \mathrm{~mm}$. The simulation requires defining the electrical and thermal properties of rice straw. The same is provided in Table 2[9-11]. The parametric study with the length of the rice stubble is performed for analysis. The length of rice straw is varied from $4 \mathrm{~cm}$ to $12 \mathrm{~cm}$ in increment of $2 \mathrm{~cm}$. The sample is heated for 10 seconds with a microwave power of 300 watts. The effect of length on the temperature profile of sample is studied. 
Table 1 Physical properties of microwave cavity

\begin{tabular}{|l|c|c|c|c|}
\hline & Width (cm) & Depth (cm) & Height (cm) & Diameter (cm) \\
\hline Microwave cavity & 26.7 & 27 & 18.8 & - \\
\hline Waveguide & 5 & 7.8 & 1.8 & - \\
\hline Glass plate & - & - & 0.6 & 22.7 \\
\hline Stubble outer diameter & - & - & - & 0.6 \\
\hline Stubble inner diameter & - & - & - & 0.1 \\
\hline
\end{tabular}

Table 2 Electrical and thermal properties of rice straw

\begin{tabular}{|l|c|c|c|c|}
\hline & Rice stubble & Glass & Air & Copper \\
\hline $\begin{array}{l}\text { Relative permittivity, } \\
\mu_{r}\end{array}$ & $3.042-0.086 * \mathrm{j}$ & 2.55 & 1 & 1 \\
\hline $\begin{array}{l}\text { Relative permeability, } \\
\varepsilon_{r}\end{array}$ & 1 & 1 & 1 & 1 \\
\hline $\begin{array}{l}\text { Electrical conductivity, } \\
\sigma(\mathrm{S} / \mathrm{m})\end{array}$ & 0.000414 & 0 & 0 & $5.99 \mathrm{e} 7$ \\
\hline $\begin{array}{l}\text { Thermal conductivity, } \\
k\left(\mathrm{~W} / \mathrm{m}^{-2} \mathrm{k}^{-1}\right)\end{array}$ & 0.053 & 23 & $26.24 \mathrm{e}-3$ & 400 \\
\hline $\begin{array}{l}\text { Density, } \rho\left(\mathrm{kg} / \mathrm{m}^{3}\right) \\
\text { Heat capacity at } \\
\text { constant pressure, } C_{p} \\
\left(\mathrm{~J} / \mathrm{kg}^{-1} \mathrm{k}^{-1}\right)\end{array}$ & $2.4 \mathrm{e} 3$ & 300 & 1.1839 & 8960 \\
\hline
\end{tabular}

The 3D arrangement of cavity is shown in Fig. 1. The rectangular cavity carries three objects viz. the rotating table and the cylindrical shape vertically placed rice straw. In the practical scenario, It is essential to assume the random orientation of rice straw however the vertical placement of rice straw enable detailed analysis in respect to important parameters.
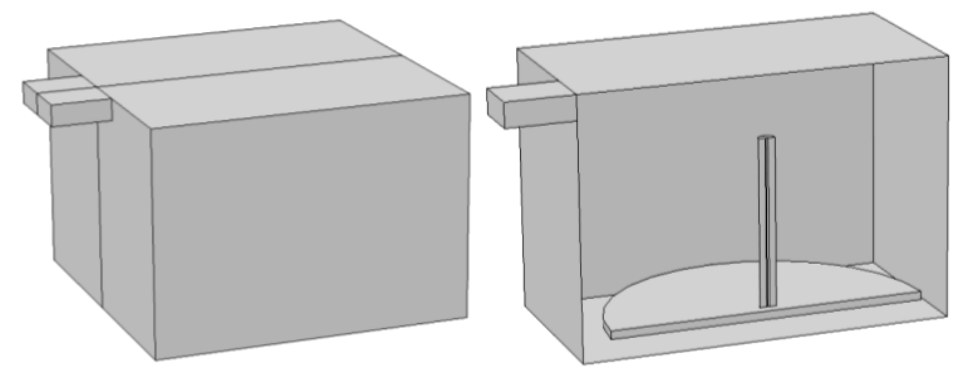

Figure 1. Half geometry of the microwave system

However, the geometry in Fig. 1 is made symmetrical to reduce the simulation time and hence the processor requirements. The symmetry allows the reduction of the geometry to half.

The microwave system in Fig. operates at a frequency of $2.45 \mathrm{GHz}$ with maximum power of $300 \mathrm{~W}$. The walls of the microwave cavity are made up of copper with the rice stubble placed at the center of a non-rotating glass plate.

The multiphysics computation requires meshing of the 3D structure to solve differential equations. The options are to choose between uniform meshing and non-uniform meshing. The non-uniform meshing controls the meshing density as per the requirement of physics. Hence, the physics-controlled mesh is chosen for the simulation with the element size in range of fraction of millimeters. The meshing comprises of tetrahedral element. The meshing of 3D geometry is shown in Fig. 2. 

of Biomass

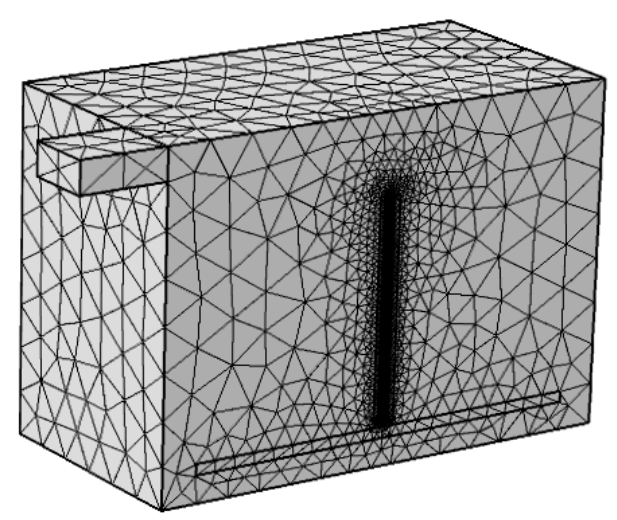

Figure 2. Meshing of 3D geometry of the model

\subsection{Governing Equations}

The meshing of 3D structure is followed by definition of equations which help in simultaneously solving the electromagnetics and heat and mass transfer equations. The electromagnetic principles are governed by Maxwell's equation and given in equation 1[12].

$$
\nabla \times\left(\mu_{r}^{-1} \nabla \times E\right)-\frac{(2 \pi f)^{2}}{c^{2}}\left(\varepsilon_{r}-\frac{j \sigma}{\omega \varepsilon_{0}}\right) E=0
$$

Here $\mu_{r}$ is relative permeability of material, $\varepsilon_{r}$ is the relative permittivity and $\varepsilon_{0}$ is free space permittivity $(\mathrm{F} / \mathrm{m}), \sigma$ is electric conductivity of material $(\mathrm{S} / \mathrm{m}), f$ is the frequency of operation of microwave and $c$ is speed of light, $2.9979 \times 10^{8} \mathrm{~m} / \mathrm{s},, E$ is the electric field $(\mathrm{V} / \mathrm{m})$.

The heat and mass transfer equations are governed by thermodynamics principles and are defined in equation 2[13].

$$
\rho C_{p} \frac{\partial T}{\partial t}=\nabla(k \nabla T)+Q
$$

Here $Q$ represents heat produced from the applied energy, $\rho$ is the density of material under test $\left(\mathrm{kg} / \mathrm{m}^{3}\right), k$ is the thermal conductivity of the material $\left(\mathrm{W} / \mathrm{m}^{-2} \mathrm{k}^{-1}\right)$, and $T$ is the temperature in kelvin $(\mathrm{K}), C_{p}$ is the specific heat capacity $\left(\mathrm{J} / \mathrm{kg}^{-1} \mathrm{k}^{-1}\right)$.

The equations defined above are solved as per the boundary conditions. The boundary conditions are essential and important aspect of heterogenous and Multiphysics simulations. The impedance boundary conditions are defined for cavity and waveguide walls. It is considered in the paper that the field penetrate to a short distance outside the boundary and hence the conditions are governed by equation 3 . The boundary conditions are visible in fig 3 and implies the applied impedance boundary condition on the geometry.

$$
\sqrt{\frac{\mu_{0} \mu_{r}}{\varepsilon_{0} \varepsilon_{r}-j \frac{\sigma}{\omega}}} n \times H+E-(n . E) n=\left(n . E_{s}\right) n-E_{s}
$$






Figure 3. Impedance boundary condition

The previous sections discuss the symmetry followed in the design of the structure. Hence, the symmetry boundaries are defined as PMC (perfect magnetic conductor) boundary. It leads to equation 4 and these boundaries are thermally insulated. The applied magnetic field boundary condition is depicted in Fig 4.

$$
n \times H=0
$$

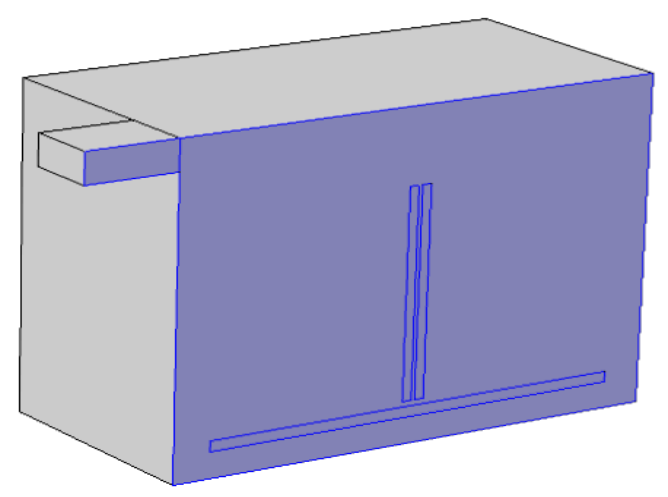

Figure 4. Perfect magnetic conductor boundary condition

The port boundary condition at the inlet as shown in Fig. 5 is excited by a electromagnetic wave operating frequency of $2.45 \mathrm{GHz}$. The applied port boundary condition on the geometry is shown in Fig. 5. The microwave power is kept at 300 watts.

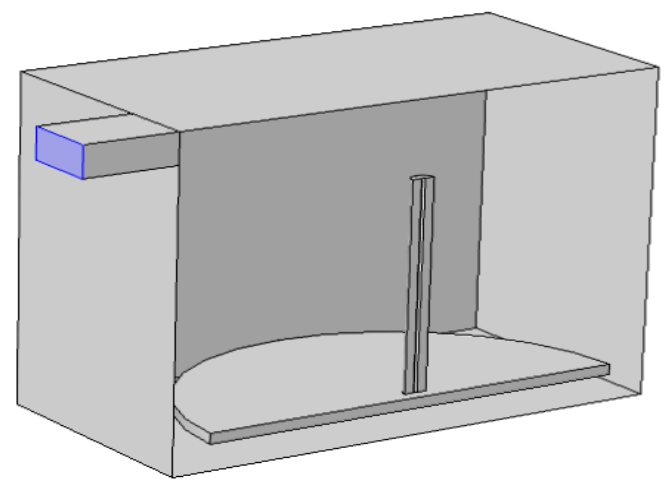

Figure 5. Port boundary condition 
While the simulation model analyzes the characteristics parameters, the need is to define the assumptions to complete the model. The assumptions are essential as the model under test has some uncertain variables

- The air flow inside the microwave cavity is not modelled.

- The rice stubble is assumed to be isotropic and homogeneous.

- The dielectric properties and thermal conductivity of the crop stubble are independent of the temperature rise.

- Simulation is performed at a single frequency of $2.45 \mathrm{GHz}$ with a rectangular wave guide.

- The position of crop stubble is fixed in space and thus the glass plate is not rotating.

\section{RESULTS AND DISCUSSION}

The distribution of the electric field in the microwave cavity at $300 \mathrm{~W}$ power at plane of symmetry as shown in Fig 4. It is clear from the Fig. that the maximum electric field is $4 \times 10^{4}$ $\mathrm{V} / \mathrm{m}$ near the waveguide. The weak spots of electric field has the value is $0.5 \times 10^{4} \mathrm{~V} / \mathrm{m}$. It clarifies the non-uniform distribution of electric field in the microwave cavity. A strong electromagnetic field at a particular position results in more heating of RS as compared to heating of RS at a position where electromagnetic field is weak.

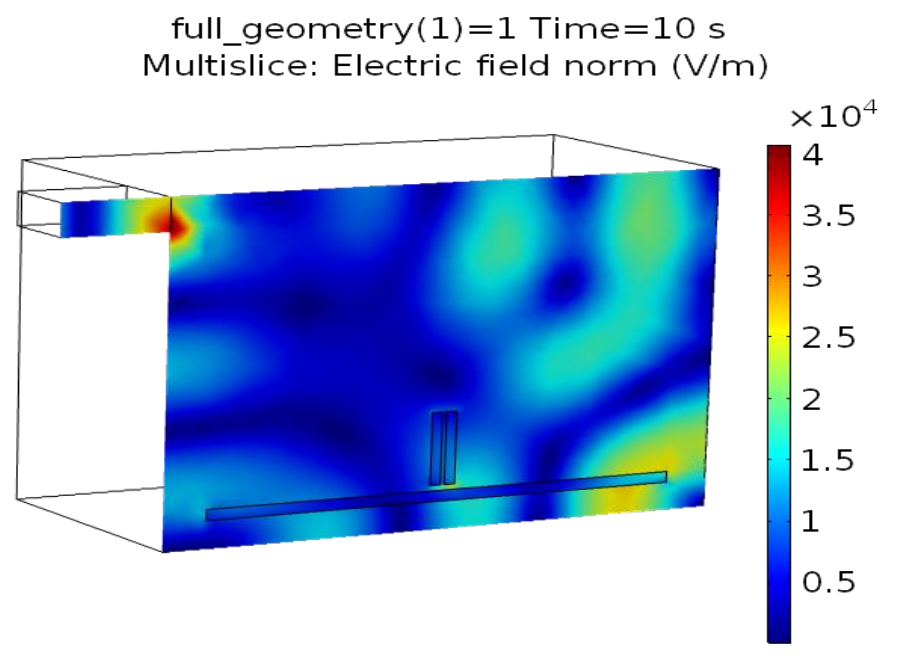

Figure 6. Distribution of electric field inside the cavity

The temperature profile in the rice straw is given in the Fig. 7. The length is varied from $400 \mathrm{~mm}$ to $12000 \mathrm{~mm}$. Due to the low thermal conductivity of the rice straw, generated heat is not able to conduct along the length of stubble at a fast pace. Thus, hot spot is created on the lower edge of the rice straw and the variation in temperature profile is observed. 
Varinder Singh, Nitin Saluja and Amrinder Singh

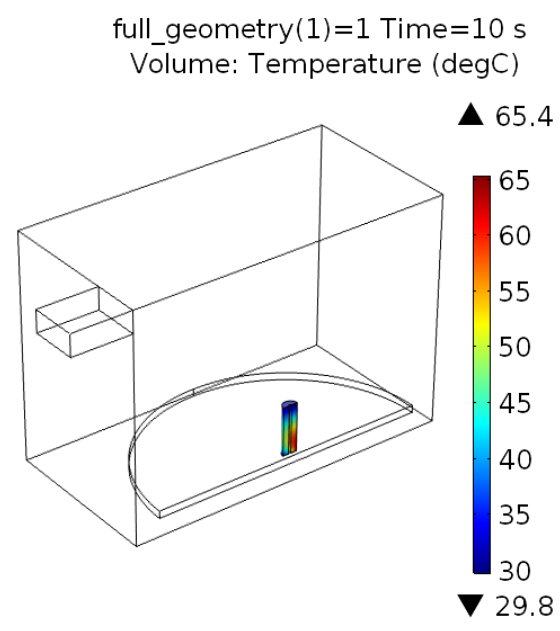

(a) $4 \mathrm{~cm}$

full_geometry $(1)=1$ Time $=10 \mathrm{~s}$ Volume: Temperature $(\mathrm{deg} C)$

A 66.3

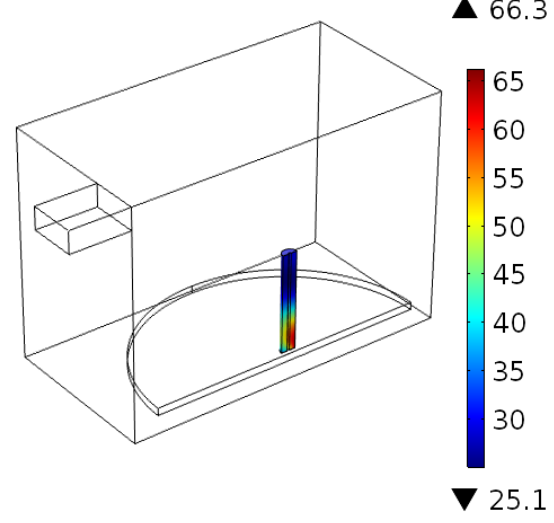

(c) $8 \mathrm{~cm}$

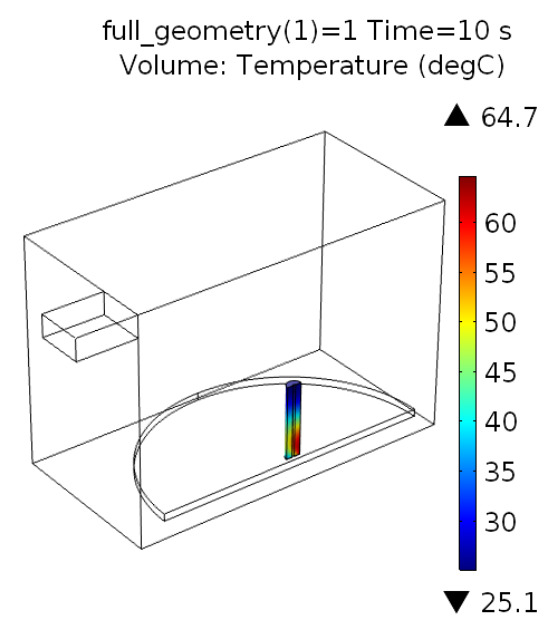

(b) $6 \mathrm{~cm}$

full_geometry $(1)=1$ Time $=10 \mathrm{~s}$ Volume: Temperature $(\mathrm{deg} \mathrm{C})$

$\Delta 68.7$

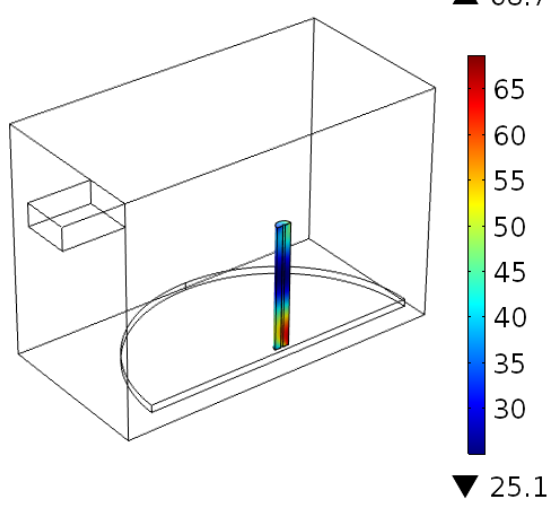

(d) $10 \mathrm{~cm}$

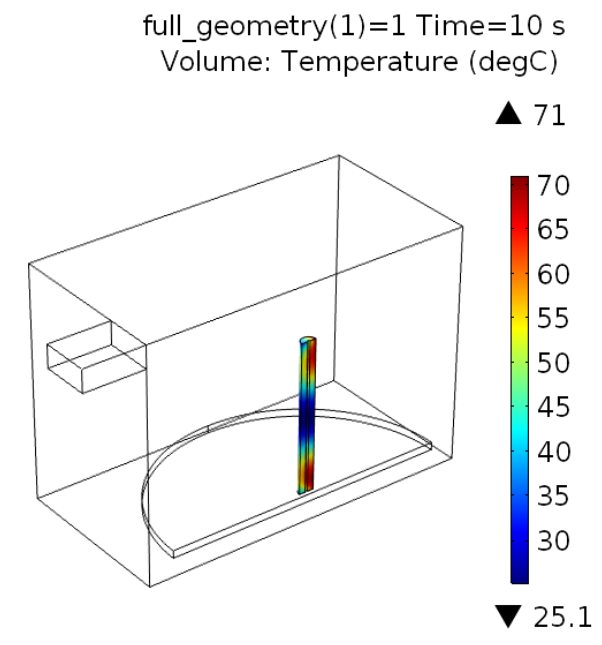

(e) $12 \mathrm{~cm}$

Figure 7 Temperature profile in different lengths of rice stubble 
The lengths are compared after the normalization of the length. The factor normalized axial variable is introduced as $\chi=\mathrm{x} / \mathrm{L}$. The parameter is used in the analysis, here $\mathrm{x}$ is the length along vertical axis where temperature is measured, and $\mathrm{L}$ is the length of the rice stubble. As shown in the fig. 8, the length of the rice stubble has significant impact on the temperature profile along its length. The graph clarifies that the high amount of variation in temperature of rice straw along the length. In contrast, when the length of the RS start increasing from $6 \mathrm{~cm}$ to $12 \mathrm{~cm}$, the exponential decay is not observed. The large size of the rice straw results in variation in form of one minima. Hence the level of non-uniformity is reduced. The practical scenario involve multiple modes interacting with multiple rice straw strands at a time. It will result in more uniform heating and hence drying of the rice straw. For a length of $12 \mathrm{~cm}$, the temperature profile on the top edge and bottom edge are symmetrical. This shows a dumbbell like distribution of temperature in the long lengths. This is attributed to the low dielectric loss value of rice stubble. In general heating, one would expect that the maximum heating would be in the sample of $4 \mathrm{~cm}$ length, but in this study, it has been observed that the maximum heating occurred in the sample of $12 \mathrm{~cm}$ length. The nonuniformity in temperature profile also indicates that the heat generation rate is much faster as compared to heat transfer rate in RS due to low thermal conductivity.

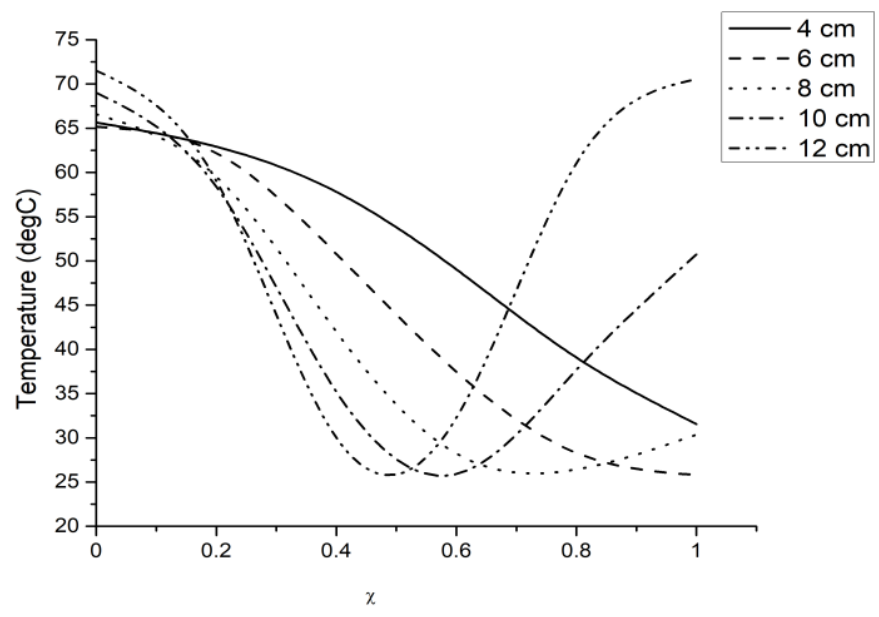

Figure 8. Temperature distribution along the length of rice stubble for different lengths

It is expected that the cutting mechanism of bulk rice straw results in uneven length of the rice straw. Hence the results discussed in the section suggests two essential points which can help optimizing the process for immediate and energy efficient drying. The first consideration is that the heat generation is faster than the heat conduction. Hence the heat conduction can't help in achieving the uniform pattern in rice straw. Further, the rice straw should be cut into small pieces but the size should be kept between $8 \mathrm{~cm}$ to $12 \mathrm{~cm}$.

\section{CONCLUSION}

This paper establishes that the microwave energy results in non-uniform heating and hence drying of the object under test. Hence it is important to optimize the process of microwave drying before using it for bulk processing. This paper considers the detailed analysis of single strand of rice straw applied to microwave energy for immediate drying. It is essential to cut rice straw according to a particular size before applying it to microwave cavity. The optimization of rice straw is achieved with the help of Multiphysics simulation. It is observed through temporal (with respect to time) simulation that the heat generation in microwave cavity is more than heat transfer through conduction. Hence the heat conduction doesn't play 
a role in achieving the uniform heating for microwave drying process. Also, it is observed that the larger size of rice straw should be expected to generate better uniformity. It is suggested that the rice straw should have length between $8 \mathrm{~cm}$ to $12 \mathrm{~cm}$ to achieve uniform drying process.

\section{ACKNOWLEDGMENTS}

We are thankful to Chitkara University Research and Innovation Network for offering software access.

\section{FUNDING}

This research did not receive any specific grant from funding agencies in the public, commercial, or not-for-profit sectors.

\section{REFERENCES}

[1] Agency, I.E., CO2 emissions from fuel combustion. 2018.

[2] Vivek, N., et al., Bio-butanol production from rice straw-recent trends, possibilities, and challenges. 2019. 7: p. 100224.

[3] Huang, Y., et al., Microwave torrefaction of rice straw and pennisetum. Bioresource technology, 2012. 123: p. 1-7.

[4] Amer, M., et al., The effect of microwave drying pretreatment on dry torrefaction of agricultural biomasses. 2019. 286: p. 121400-121400.

[5] Motasemi, F. and M.T. Afzal, A review on the microwave-assisted pyrolysis technique. Renewable and Sustainable Energy Reviews, 2013. 28: p. 317-330.

[6] Wäppling-Raaholt, B. and T. Ohlsson, Influence of food geometry and dielectric properties on heating performance, in Development of Packaging and Products for Use in Microwave Ovens. 2009, Elsevier. p. 38-65.

[7] Yu, S., et al., Three-dimensional simulation of a novel microwave-assisted heating device for methyl ricinoleate pyrolysis. 2019. 153: p. 341-351.

[8] Motasemi, F. and A.J.F. Gerber, Multicomponent conjugate heat and mass transfer in biomass materials during microwave pyrolysis for biofuel production. 2018. 211: p. 649660 .

[9] Zulkifli, N.A., et al. Analysis of Dielectric Properties On Agricultural Waste for Microwave Communication Application. in MATEC Web of Conferences. 2017. EDP Sciences.

[10] Yuan, S., et al., Rapid co-pyrolysis of rice straw and a bituminous coal in a highfrequency furnace and gasification of the residual char. 2012. 109: p. 188-197.

[11] Lu, L., et al. The Prediction of Thermal Conductivity of Agricultural Residues from Straw for Biomass Energy. in Advanced Materials Research. 2013. Trans Tech Publ.

[12] Pitchai, K., et al., Coupled electromagnetic and heat transfer model for microwave heating in domestic ovens. 2012. 112(1-2): p. 100-111.

[13] Pitchai, K., Electromagnetic and heat transfer modeling of microwave heating in domestic ovens. 2011. 